\title{
Acute Submandibular Tumour in Myelodysplastic Syndrome: A Rare Report
}

María Luisa Navarrete $^{1 *}$, Fernando Morell ${ }^{2}$, Juan Fernando Fuentes ${ }^{1}$, Nuria Ortiz ${ }^{1}$, Pilar Coscojuela ${ }^{3}$ and Angel García ${ }^{3}$

${ }^{1}$ Department of Otorhinolaryngology, Vall d'Hebron Hospital, Autonomous University of Barcelona, Spain

${ }^{2}$ Department of Pneumology, Vall d'Hebron Hospital, Autonomous University of Barcelona, Spain

${ }^{3}$ Department of NeuroRadiology and Pathology, Vall d' Hebron Hospital, Autonomous University of Barcelona, Spain

\begin{abstract}
Summary
Myelodysplastic syndromes (MDS) are hematological diseases with a wide clinical spectrum of manifestations. We present a 66 year old patient who was referred to our department with an acute submandibular growth that was first noticed 2 weeks ago. It hasn't responded to standard treatment. Multiple studies were performed, and they revealed in filtrate of mielodisplastic cells, refractory anemia with excess blasts in transformation (RAEB-T) subtype according to the FAB classification. Combined chemotherapy couldn't stop the disease's progression and the patient died from a pulmonary infection 3 months after the onset of symptoms. Leukemic infiltration of the submandibular gland in mielodisplastic syndrome hasn't been previously described in literature, so this seems to be the first reported case of extra medullary hematopoiesis resulting in an acute submandibular tumor in a patient with REAB-T.
\end{abstract}

Keywords: Submandibular gland; Myelodysplastic syndrome

\section{Introduction}

Myelodisplatic syndromes, also known as the preleukemic syndromes, quiescent leukemias or refractory anemias, constitute a group of hematological disorders characterized by the proliferation of an abnormal clone of bone marrow cells that result in alterations in maturing of the three blood cell lines. This entity is characterized by the presence of hyperplasic bone marrow that produces non-functioning cells that die before reaching the peripheral bloodstream (marrow abortion). This causes pancytopenia and dysplastic or immature cells in all three cell lines in the bloodstream [1].

According to the FAB classification [2], myelodisplastic syndromes are divided according to five different subtypes: 1. Refractory Anemia (RA) 2. Refractory anemia with ringed sideroblasts (RARS) 3. Refractory anemia with excess blasts (RAEB): the most frequent variant (20-50\% of all cases). 4. Refractory anemia with excess blasts in transformation (RAEB-T): the least frequently seen (10\%), yet the one that entails the worst prognosis, average survival of 5 months 5 . Chronic myelomonocytic leukemia (CMML).

Even though Myelodysplastic syndromes are acquired diseases, most of them idiopathic, chromosomic abnormalities can be seen in $40-60 \%$ of the cases. The disease affects mostly older individuals, with a marked male predominance [1-3].

The usual clinical presentation is pancytopenia with symptoms resulting from anemia, recurrent infections, fever from leukopenia and bleeding diathesis from thrombocytopenia. Visceromegaly from leukemic cell infiltration is less commonly seen, with the liver, spleen and lymph nodes usually affected. Multiple associated syndromes like relapsing polychondritis, AIDS, rheumatoid arthritis, etc can also be present. They frequently evolve to acute leukemia, usually myeloid subtype [3].

Diagnosis is based on laboratory hematological techniques and the fundamental treatment is life support measures combined with chemotherapy if there are excess blasts.

\section{Case Report}

We present a 66 year old male, with a previous history of type
II diabetes mellitus and hypercholesterolemia who arrived at the emergency department complaining of odynophagia and a left submandibular growth. He referred the symptoms started ten days before and had not resolved with oral antibiotics and non steroid antiinflammatory drugs.

The patient's presenting symptoms were severe odynophagia, muscle pain, asthenia, fever with chills and diaphoresis, and a tender submandibular growth. Upon physical examination, a bilateral submandibular mass was found. It was hard, tender to the touch, bigger on the left side and fixed to the deep tissues of neck. The floor of the mouth was also tender to the touch and the Wharton's ducts where swollen as well. The patient had multiple enlarged laterocervical lymph nodes on the left side. Hepathomegaly $4 \mathrm{~cm}$ below the ribcage was found in general exploration.

The ED blood work showed anemia, leucocytosis with left deviation and immature cells and moderate thrombocytopenia. The ED chest $\mathrm{x}$-ray showed what appeared to be a large mass in the anterior in the anterior mediastinum (Figure 1). An initial diagnosis of infected submandibular mass was made and empirical treatment with intravenous antibiotics and anti-inflammatory drugs were started. Emergency cervical and thoracic CT scans were performed.

The cervico-thoracic CT scan (Figure 2) showed palatine and lingual tonsillar enlargement, with an enlarged left submandibular gland. There was no apparent acute inflammatory process. Enlarged left laterocervical lymph nodes (larger than $1 \mathrm{~cm}$ diameter) near the submandibular gland were also evident. A large $9 \mathrm{~cm} \times 9 \mathrm{~cm}$ thoracic

*Corresponding author: ML Navarrete, Department of Otorhinolaryngology Vall d' Hebron Hospital, Autonomous University of Barcelona, Spain, E-mail: mlna@telefonica.net

Received February 08, 2012; Accepted March 07, 2012; Published March 09, 2012

Citation: Navarrete ML, Morell F, Fuentes JF, Ortiz N, Coscojuela P, et al. (2012) Acute Submandibular Tumour in Myelodysplastic Syndrome: A Rare Report. J Tissue Sci Eng 3:115. doi:10.4172/2157-7552.1000115

Copyright: (c) 2012 Navarrete ML, et al. This is an open-access article distributed under the terms of the Creative Commons Attribution License, which permits unrestricted use, distribution, and reproduction in any medium, provided the original author and source are credited. 
mass was evident in the anterior mediastinum, suggestive of thymoma (Figure 3).

A fine-needle aspiration biopsy of the left submandibular gland was performed, and informed as compatible with an acute inflammatory process, with no malignant cells found.

Due to the patient's clinical deterioration and a lack of diagnosis, an excisional biopsy of the left submandibular gland was performed. The anatomopathologicical study reported glandular infiltration by blastic forms of myeloid cells (Figures 3 and 4 ).

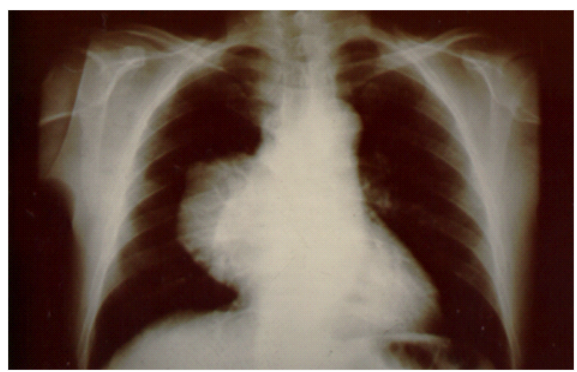

Figure 1: AP chest X-ray where a large mass in the anterior mediastinum can be seen.

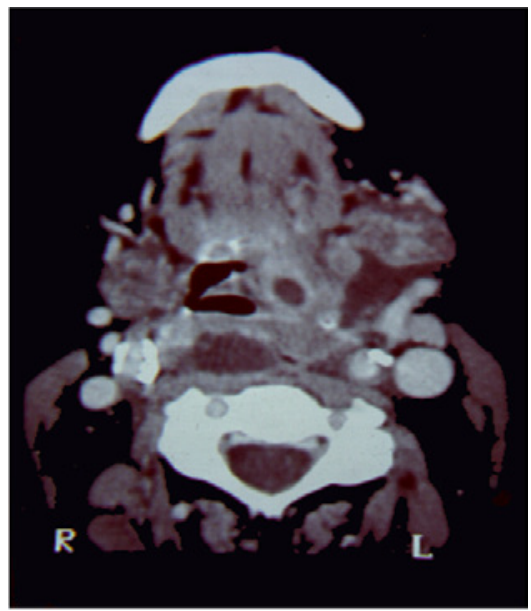

Figure 2: Axial contrast enhanced-CT at the oropharyngeal level that shows an enhanced tonsilar lesion with affectation of ipsilateral base tongue. Also a $1 \mathrm{~cm}$ enlarged lympbh node can be seen.

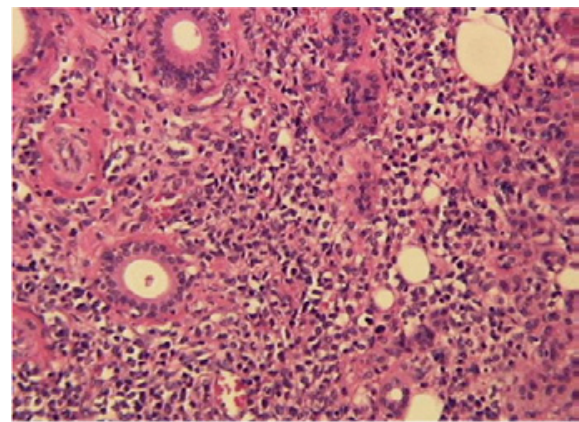

Figure 3: Anatomopathological slide of the submandibular gland. A strong infiltrate of round cells with blastic appearance, involving stroma and lipocytic tissue producing lymphoepithelial lesions is shown HE 400x.

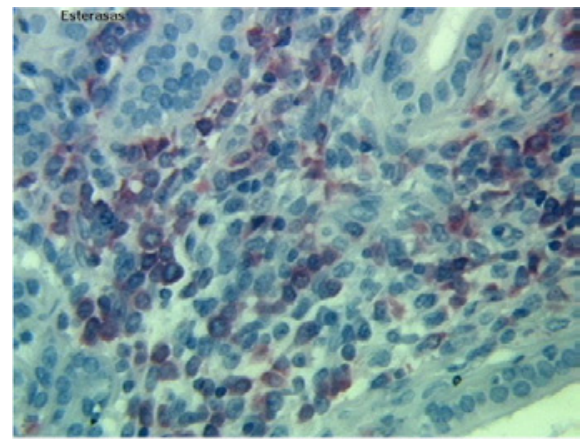

Figure 4: Anatomopathological slide of the submandibular gland. The immunohistochemical stain of esterases identifies the blastic cells by their cytoplasmic overexpression PAP 400x.

With the presumptive diagnosis of a hematologic disease the patient was referred to the Hematology Department where further studies were performed. Bone marrow aspirate cytology as well as biopsy with immunohistochemical studies helped arrive to the final diagnosis of type RAEB-T myelodisplastic syndrome. A mediastinum mass biopsy was also performed, reporting a thymoma, with no apparent relation to the myelodysplastic disease.

Specific chemotherapy with cytarabine (ARA-C), ethopoxide (VP-16) and idarrubicine was started, without any apparent response. The patient suffered a bilateral interstitial pneumonia and died from complications of it, a month and a half after his first ED visit.

\section{Discussion}

The term extramedullary myeloid cell tumour (EMT), first described in the literature by Davey et al. [4] now a day's includes all the extramedullary complications of leukemia, such as granulocytic sarcoma [5] and leukemia cutis [6,7], including the non-mass-forming leukemical infiltrates. While most EMTs follow an acute or chronic myeloid leukemia (AML or CML) a significant proportion of EMTs can be observed during the course of a myelodysplastic syndrome. Four cases have been just reported of EMT with positive fine-needle aspiration biopsy [8]; all these patients were suffering from refractory anemia with excess of blasts in transformation REAB-T; these lesions were located in the soft tissues and were studied by the same authors, except one of multiple lymphatic node localizations in a patient with REAB-T [9].

Extramedullary myeloid tumour (EMT) is an uncommon disease mostly diagnosed in patients affected by acute or chronic myeloid leukaemia or, more rarely, by a myelodysplastic syndrome, among which the most frequent is refractory anemia with excess of blasts in transformation RAEB-T. The prognosis meaning of EMT is still unclear, although the presence of trilineage EMT is often considered to be a negative prognostic factor [9].

The extramedullary myeloid cell tumour (EMT) may precede or complicate the course of acute or chronic leukemias and various types of MDS, including RAEB-T [10]. Relating to otolaryngological presentations, one case of laryngeal infiltration was reported previously in chronic myelomonocytic leukemia [11], and another one of relapsing polychondritis associated with myelodysplastic syndrome [12] Nevertheless, ours is the first reported case where a myelodysplastic syndrome is presented as an acute submandibular tumour. It represents an important possible diagnosis that must be excluded when abnormal 
Citation: Navarrete ML, Morell F, Fuentes JF, Ortiz N, Coscojuela P, et al. (2012) Acute Submandibular Tumour in Myelodysplastic Syndrome: A Rare Report. J Tissue Sci Eng 3:115. doi:10.4172/2157-7552.1000115

blood analysis findings are accompanied by an acute submandibular tumour.

\section{References}

1. Bessis M, Lessin LS (1983) Morphology of the erythron. In: Ernest Beutler, Marshall A. Lichtman, Barry S. Coller Thomas J, Kipps, Williams Hematology (Fifh Edition) Chapter 26 $6^{\text {th }}$ 257-279.

2. Ludlam CA (1990) Clinical Hematology. Edited by Churchill Livingstone 247253.

3. Lind SE, The hemostatic system In: Handin I, Lux SE, StosselTP (1992) Blood principles and Practice of hematology. Ed. by JB Lippincott Company chapter 33: 377- 405.

4. Davey FR, Olson S, Kurec AS, Eastman-Abaya R, Gottlieb AJ, et al. (1988) The immunophenotyping of extramedullary myeloid cell tumors in paraffin. embedded tissue sections. Am J Surg Pathol 12: 699-707.

5. Edenfield W, Shields D, Dawson N (1967) Extramedullary myeloid cell tumors in acute nonlimphocytic leucemia. In: Rappaport, $\mathrm{H}$. Tumors of the hematopoietic system: atlas of tumor pathology, sec.3, fas.8. Washington DC, Armed Forces Institute of Pathology 241-247.
6. Su WP, Buechner SA, Li CY (1984) Clinicopathologic correlations in leukemia cutis. J Am Acad Dermatol 11: 121-128.

7. Longacre TA (1993) Smoller, BR Leukemia cutis. Am J Clin Pathol 100: 276284

8. Gujral S, Kumar R, Jain P, Sharma A, Gupta S, et al. (1999) Fine needle aspiration of extramedullary myeloid cell tumor in myelodysplastic syndrome: A report of three cases. Acta Cytol 43: 647-651.

9. Fulciniti F, Zeppa P, Marino G, Martinelli V, Ciancia R, et al. (2003) Lymphnode localization of extramedullary myeloid cell tumor in myelodysplastic syndrome: report of one case diagnosed by fine-needle cytology. Diagn Cytopathol 3: 136139.

10. Byrd JC, Edenfield WJ, Dow NS, Aylesworth C, Dawson N (1996) Extramedullary mieloid cell tumors in myelodisplastic syndromes: Not a True Indication of Impeding Acute Myeloid Leukaemia. Leukemya and Lymphoma 21: 153-159.

11. Brito-Babupulle F, Barbatis C, Whitmore DN (1989) Laryngeal infiltration in chronic myelomonocytic leukaemia. Clin Lab Haematol 11: 403-406.

12. Shirota T, Hayashi O, Uchida H, Tonozuka N, Sakai N, et al. (1993) Myelodysplastic syndrome associated with relapsing polychondritis: unusual transformation from refractory anemia to chronic myelomonocytic leukemia Ann Hematol 67: 45-47. 